\title{
The Relative Impact of Ice Fall Speeds and Microphysics Parameterization Complexity on Supercell Evolution
}

\author{
Nicholas M. Falk, Adele L. Igel, And Matthew R. Igel \\ Department of Land, Air and Water Resources, University of California, Davis, Davis, California
}

(Manuscript received 29 November 2018, in final form 26 April 2019)

\begin{abstract}
The use of bin or bulk microphysics schemes in model simulations frequently produces large changes in the simulated storm and precipitation characteristics, but it is still unclear which aspects of these schemes give rise to these changes. In this study, supercell simulations using either a bin or a double-moment bulk microphysics scheme are conducted with the Regional Atmospheric Modeling System (RAMS). The two simulations produce very different storm morphologies. An additional simulation is run for each scheme in which the diameter-fall speed relationships for ice hydrometeors are modified to be similar to those used by the other scheme. When fall speed relationships are homogenized, the two parameterization schemes simulate similar storm morphology. Therefore, despite the use of largely dissimilar approaches to parameterizing microphysics, the difference in storm morphology is found to be related to the choice of diameter-fall speed relationships for ice hydrometeors. This result is investigated further to understand why. Higher fall speeds lead to higher mixing ratios of hydrometeors at low levels and thus more melting. Consequently, stronger downdrafts and cold pools exist in the high fall speed storms, and these stronger cold pools lead to storm splitting and the intensification of a left mover. The results point to the importance of hydrometeor fall speed on the evolution of supercells. It is also suggested that caution be used when comparing the response of a cloud model to different classes of microphysics schemes since the assumptions made by the schemes may be more important than the scheme class itself.
\end{abstract}

\section{Introduction}

Despite large advances in atmospheric modeling having been made in the past decades, there remain many unanswered questions, open debates, and opportunities for improvement in atmospheric modeling. Increasing computing power is allowing modelers to increase resolution and move toward more widespread use of cloud-resolving simulations; this is making the parameterization of cloud microphysics increasingly important to understand and to perform accurately.

Cloud microphysics schemes must simulate complex processes, and the representation of these processes can differ greatly between models. There are currently two common, but fundamentally different approaches to parameterizing cloud microphysics. These two types of microphysics schemes are typically called bin schemes and bulk schemes. A full discussion of these scheme types is given by Khain et al. (2015). We briefly summarize them here. Bulk schemes typically assume a

Corresponding author: Nicholas Falk, nick.falk@colostate.edu functional form for the size distribution of hydrometeors; they predict the mass and/or number mixing ratio of each hydrometeor species. Bulk schemes that predict both properties (double-moment schemes) are increasingly used since they tend to perform better than bulk schemes that predict only one property (singlemoment schemes) (Igel et al. 2015). Some triplemoment bulk schemes additionally predict a third property, the radar reflectivity (Milbrandt and Yau 2005; Szyrmer et al. 2005; Shipway and Hill 2012; Loftus et al. 2014). Bin microphysics schemes avoid the need to predict moments of a distribution. Instead, each hydrometeor size distribution is discretized into bins that together span the size range of that species. The number and/or mass mixing ratio is predicted for each bin. This allows for bin schemes to predict size distributions that may not be consistent with the assumed distribution shape in bulk schemes. Additionally, prediction of discrete sizes allows bin schemes to simulate many phenomena more realistically than bulk models, for example, collision-coalescence. The drawback of bin schemes is their high computational cost compared to 
bulk schemes. This cost results in bin schemes being used less frequently than bulk schemes.

Many studies have shown that the choice of a bin or bulk microphysics scheme can have a large impact on the simulation of cloud and storm properties (Seifert and Beheng 2006; Morrison and Grabowski 2007; Khain et al. 2009; Li et al. 2009; Fan et al. 2012; Iguchi et al. 2012; Fan et al. 2015; Wang et al. 2013). However, because bin and bulk schemes vary in so many ways, it is often difficult to understand why the schemes result in such different simulations. It is unclear if the differences in simulations arise primarily due to the different fundamental construction of bulk and bin schemes, or if they arise primarily due to different assumptions that the schemes make when parameterizing the same process.

Certainly, the assumptions made in microphysics schemes of either type can have large impacts on simulated cloud properties (Johnson et al. 2015; Posselt 2016). Several studies in the past have focused on understanding the sensitivity of convective storms to assumptions about parameter values related to the size distribution or physical properties of hydrometeors within bulk microphysics schemes. Gilmore et al. (2004) varied the intercept parameter (and therefore indirectly the mean size and fall speed) of graupel and hail and found that simulations with larger, faster falling graupel produced stronger cold pools. Morrison and Milbrandt (2011), Van Weverberg et al. (2012), and Bryan and Morrison (2012) all also found cold pools appeared earlier and were stronger when they switched from less dense, slow falling graupel to more dense, fast falling hail. Other studies disagree. Smaller hydrometeors have larger surface area to volume ratios, so they melt faster and are associated with more latent cooling leading to stronger cold pools (van den Heever and Cotton 2004; Cohen and McCaul 2006; Xue et al. 2017). This increase in melting, along with the subsequent dynamical effects, results in storms with smaller hydrometeors having less total precipitation. However, storms with smaller or slower falling hydrometeors can have larger stratiform regions and wider areas of precipitation, since hydrometeors are slower to fall out and there is more horizontal advection of hydrometeors. This response of the stratiform region is consistent among studies even if the cold pool response is not (Adams-Selin et al. 2013; Bryan and Morrison 2012; Van Weverberg et al. 2012).

All these studies change size distribution parameters that indirectly impact the average fall speeds of hydrometeors, but the parameters in fall speed-diameter relationships can be just as important for determining the average fall speed as the size distribution parameter (McFarquhar and Black 2004). Few previous studies directly vary fall speed-diameter relationships. Bennetts and Rawlins (1981) simulated later onset of heavy precipitation and lower total precipitation when they lowered the fall speed of hail to that of rain in their early model. Adams-Selin et al. (2013) found that faster falling graupel led to more intense cold pools.

These results taken together indicate that the choice of hydrometeor diameter-fall speed relationship could have large direct impacts on storms and suggest that the sensitivity to parameters that impact the hydrometeor size distribution may in part be a result of indirectly changing the average fall speeds.

In this study, we describe a case in which the differences between simulations with a bin and a bulk scheme seem to arise primarily from different, reasonable assumptions that are made about the fall velocity of ice particles. The results suggest that the fundamentally different design of bulk and bin schemes may be less important than the shared choices that the schemes must make about hydrometeor properties, at least in some cases. This conclusion is in agreement with Adams-Selin et al. (2013) who noted that changing hail sizes (and consequent settling rates) had larger impacts on their bow echo simulations than the choice of bulk microphysics scheme. They also found changing graupel fall speeds independently of size had as large of an impact as changing graupel size and fall speed in concert. This is also in agreement with Xue et al. (2017) who found that assumptions about hydrometeor properties could make large changes in storm dynamics and thermodynamics. They also conclude that caution must be taken when comparing bin and bulk schemes. We also discuss the physical processes that cause such a large sensitivity to the fall velocity of ice particles. The simulations are described in section 2 , and the results are discussed in section 3 .

\section{Experimental design}

Four supercell simulations were run using the Regional Atmospheric Modeling System (RAMS) (Cotton et al. 2003) to test the relative sensitivity of these storms to changes in microphysical parameterizations. The domain size was $300 \mathrm{~km}$ east to west and $250 \mathrm{~km}$ north to south. Grid spacing was $1 \mathrm{~km}$ in the horizontal, and variable in the vertical with a minimum spacing of $50 \mathrm{~m}$ at the surface, a stretching factor of 1.1, and a maximum of $1 \mathrm{~km}$. The simulations were run for $3 \mathrm{~h}$ with a $4-\mathrm{s}$ time step. We used an open radiative boundary condition for outflow and a zero-gradient condition for inflow. The Coriolis force was included using a latitude of $37^{\circ} \mathrm{N}$. Radiation was parameterized using the Harrington (1997) radiation scheme and updated every $10 \mathrm{~min}$. Subgrid-scale turbulence was parameterized following 

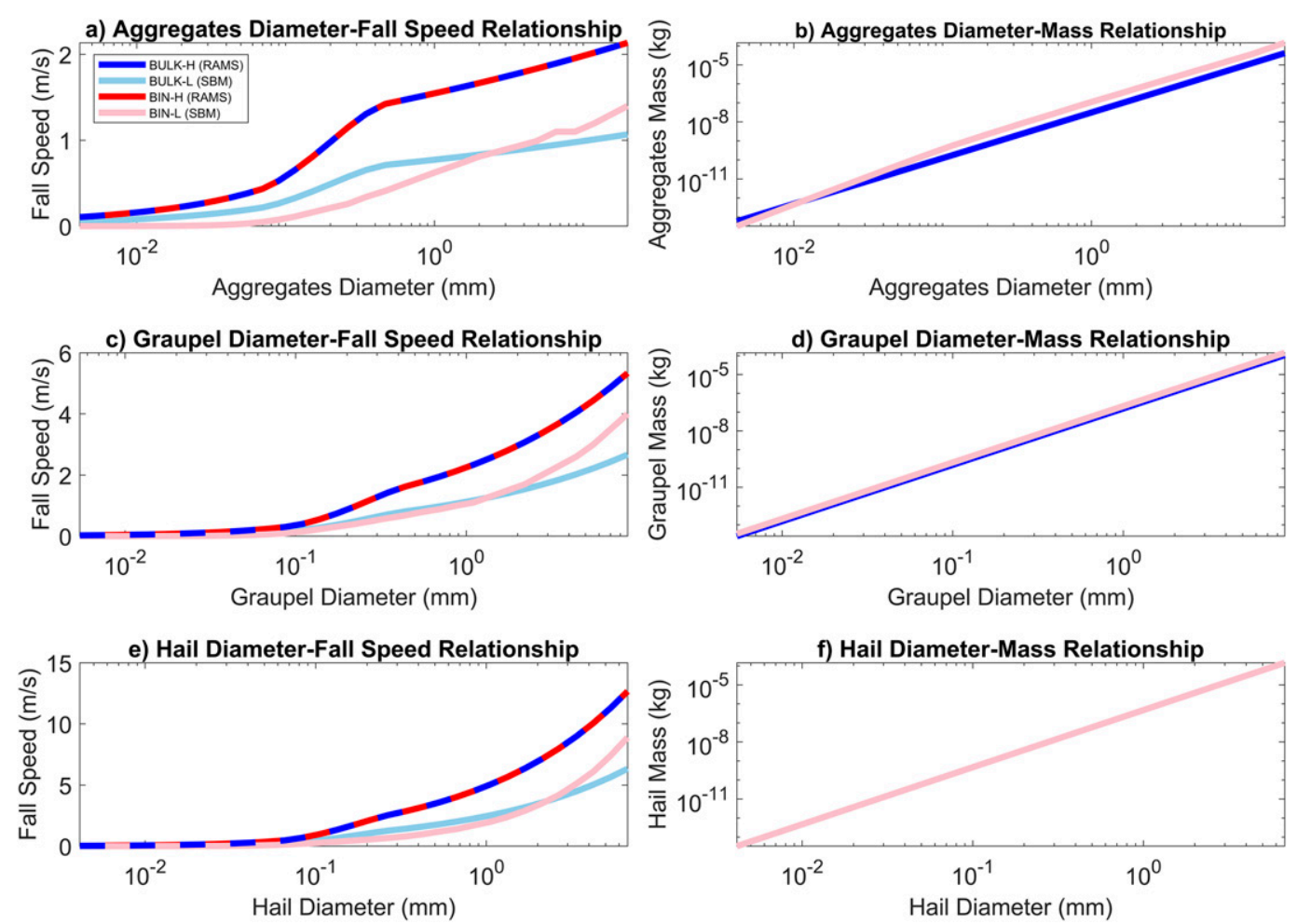

FIG. 1. (left) Fall speed-diameter and (right) mass-diameter relationships. Blue and red indicate the standard RAMS relationships used in BULK-H and BIN-H, pink indicates the standard SBM relationship used in BIN-L, and light blue indicates the modified relationship used in BULK-L. Diameter-fall speed relationship for (a) aggregates, (c) graupel, and (e) hail. Diameter-mass relationship for (b) aggregates, (d) graupel, and (f) hail.

Smagorinsky (1963) with modifications by Lilly (1962) and Hill (1974). The initial thermodynamic conditions and convective initialization are the same as those used by Grant and van den Heever (2014). Temperature and moisture profiles were initially horizontally uniform and used the analytical sounding of Weisman and Klemp (1982) with $13 \mathrm{~g} \mathrm{~kg}^{-1}$ of moisture in the boundary layer. The wind shear follows an idealized half-circle profile with speeds increasing to $32 \mathrm{~m} \mathrm{~s}^{-1}$ at $5 \mathrm{~km}$ (Weisman and Klemp 1984). There is a small amount of shear between 5 and $7 \mathrm{~km}$ and above $7 \mathrm{~km}$ the winds are constant with height. Convection was initiated using a square $2-\mathrm{K}$ warm bubble $10 \mathrm{~km}$ on a side.

Simulations were run with either the RAMS doublemoment bulk microphysics scheme (Saleeby and Cotton 2004; Saleeby and van den Heever 2013), or the Hebrew University Spectral Bin Model (SBM) (Khain et al. 2004), which is a recently added option in RAMS (Igel and van den Heever 2017). The RAMS bulk scheme has eight hydrometeor categories: cloud droplets, drizzle, rain, pristine ice, snow, aggregated snow, graupel, and hail. Pristine ice corresponds to smaller ice crystals and snow corresponds to larger sizes. The SBM on the other hand uses seven hydrometeor categories: liquid drops, three categories of ice crystals (plates, columns, and dendrites), aggregated snow, graupel, and hail.

There are many different assumptions made by the two schemes. One particularly striking difference is the diameter-fall speed relationships of aggregated snow, graupel, and hail. These three species will be hereafter referred to as "big ice" and the remaining ice categories will be referred to as "small ice." We ran one RAMS bulk simulation with its standard fall speeds and one SBM simulation with its standard fall speeds. The bulk scheme simulation with its standard fall speeds will be referred to as BULK-H and the SBM simulation with the standard SBM fall speeds will be referred to as BIN-L ( $\mathrm{H}$ for high fall speed and $\mathrm{L}$ for low fall speed). To test whether these different diameter-fall speed relationships could explain differences between the RAMS bulk and SBM simulations (see next section), we ran two additional simulations in which the diameter-fall speed relationships in each scheme were altered. A second bulk scheme simulation was run with the standard bulk scheme fall speeds for aggregated snow, graupel, and hail reduced to half in order to effectively mimic the bin scheme fall speeds. This simulation with the SBM-like fall speeds will be referred to as BULK-L. Finally, 

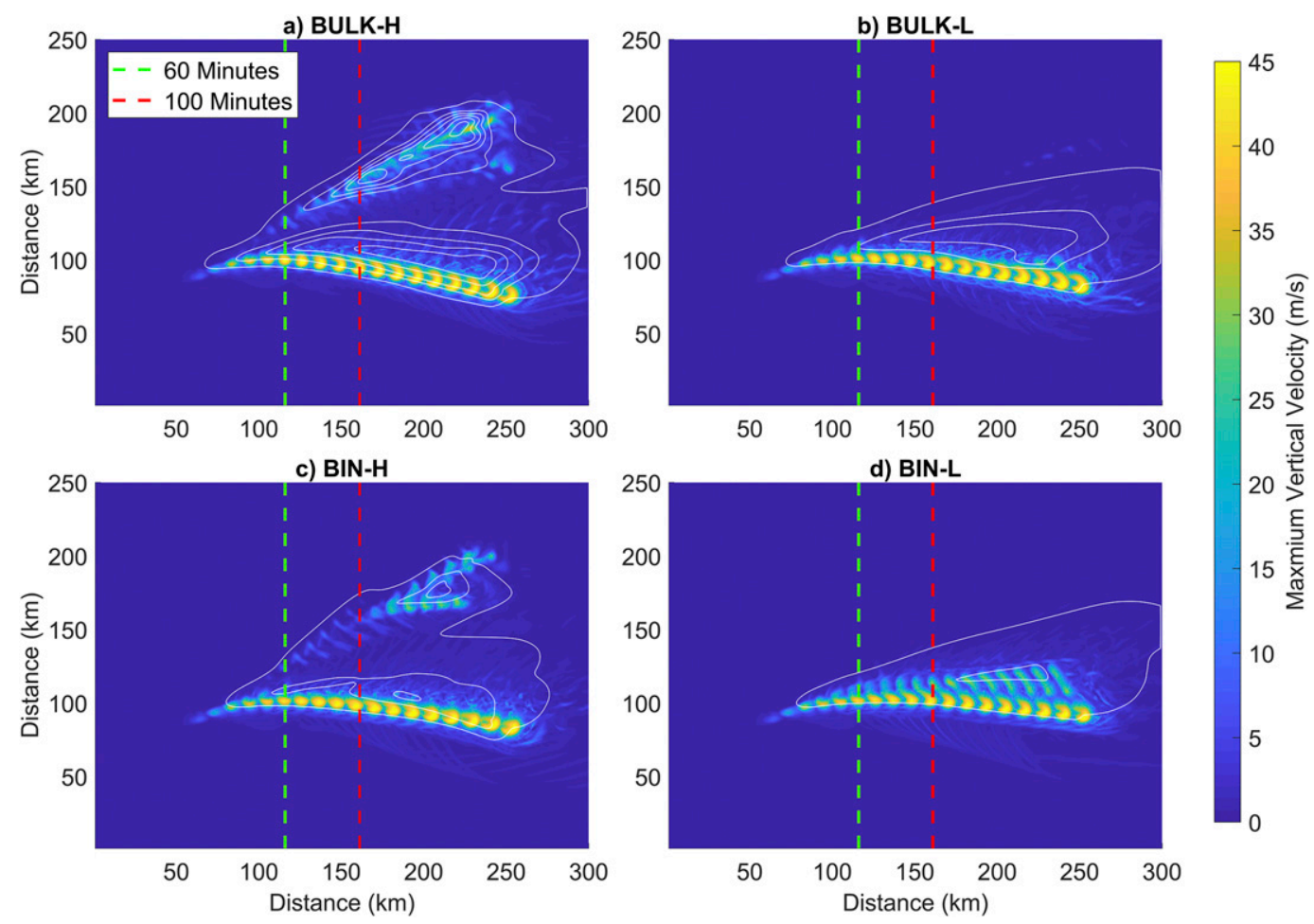

FIG. 2. Accumulated precipitation (white contours) and time and column maximum vertical velocity (shaded). Precipitation contours are drawn in white every $3 \mathrm{~mm}$ with the first at $0.1 \mathrm{~mm}$. Vertical velocity data are taken every two outputs $(10 \mathrm{~min})$. The green and red lines indicate the location of the maximum vertical velocity at 60 and $100 \mathrm{~min}$, respectively, for each storm.

a second SBM simulation was run using the bulk scheme fall speeds for big ice and will be referred to as BIN-H. Only the diameter-fall speed relationships of big ice are changed; the diameter-fall speed relationships of all other hydrometers are left unchanged. Furthermore, note that due to the use of precomputed collection kernels, the changes in fall speeds do not impact the collection rates in either BULK or BIN. Due to the structure of the code, the fall speeds impact the ventilation coefficients used for condensation and evaporation in BIN, but not in BULK.

In the RAMS bulk scheme, piecewise power-law relationships are based on data presented in Mitchell (1996). In the SBM, power-law relationships for aggregated snow and hail are based on Pruppacher and Klett (1997) and for graupel on Khain et al. (2001). The first column of Fig. 1 shows each relationship for $1000 \mathrm{mb}$. The diameter-fall speed relationships used by the two schemes differ by $50 \%$ or more for most sizes across all three categories, with the RAMS bulk scheme fall speeds being greater than those in SBM in all cases. These differences are not related to the choice of massdiameter relationship that is shown in the second column of Fig. 1. For graupel and hail, the mass-diameter relationships are similar and the same, respectively.
For aggregated snow, the mass-diameter relationships differ substantially; however, the SBM diagnoses higher mass and lower fall speed for the same diameter. Therefore, the mass-diameter relationships do not explain why the fall speed relationships disagree. Instead, the different relationships appear to simply be different choices made by the scheme developers and represent some degree of uncertainty present in empirical data. We will reiterate; both sets of relationships are reasonable and based on published literature. Furthermore, we make no judgment here about which set of fall speed relationships is more realistic or appropriate, and in the results that follow, no judgment about which simulation is considered to be the most "correct." We consider all simulations to be equally likely representations of reality.

\section{Results}

\section{a. Supercell evolution}

Figure 2 shows the column and time (from output every $10 \mathrm{~min}$; shaded) maximum velocity and accumulated precipitation (white contours) for all four simulations. The immediately notable difference in Fig. 2 is that both 
a) Rain

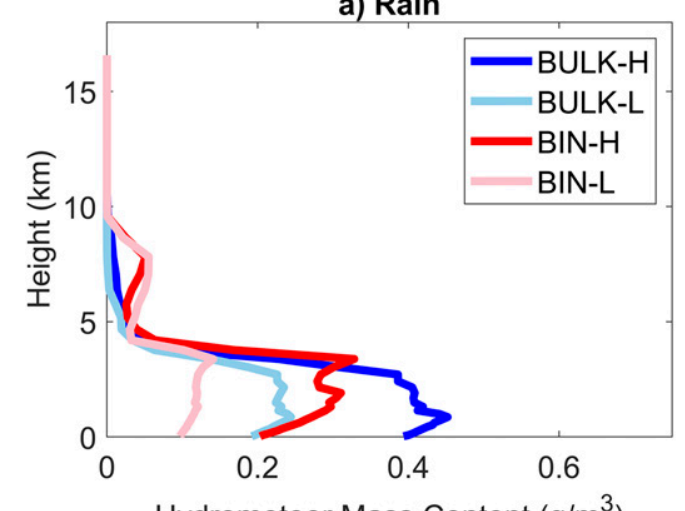

Hydrometeor Mass Content $\left(\mathrm{g} / \mathrm{m}^{3}\right)$

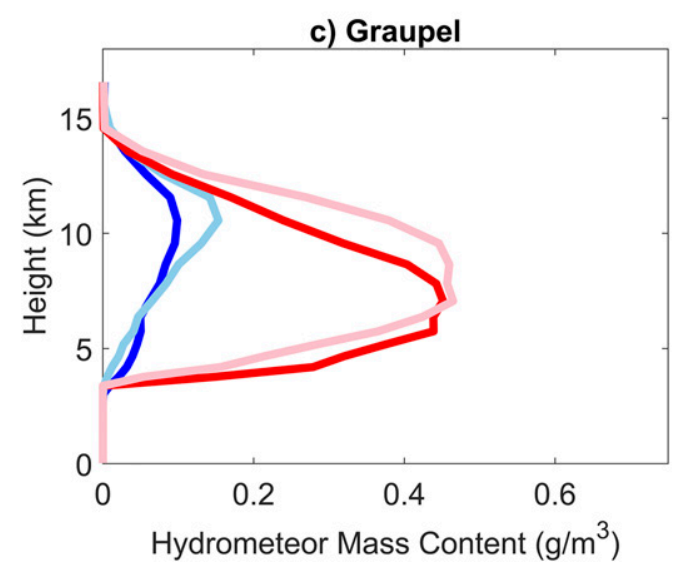

b) Hail

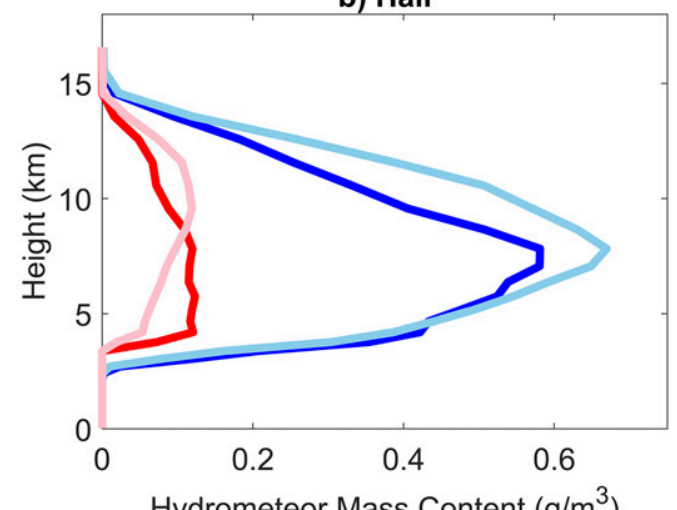

Hydrometeor Mass Content $\left(\mathrm{g} / \mathrm{m}^{3}\right)$

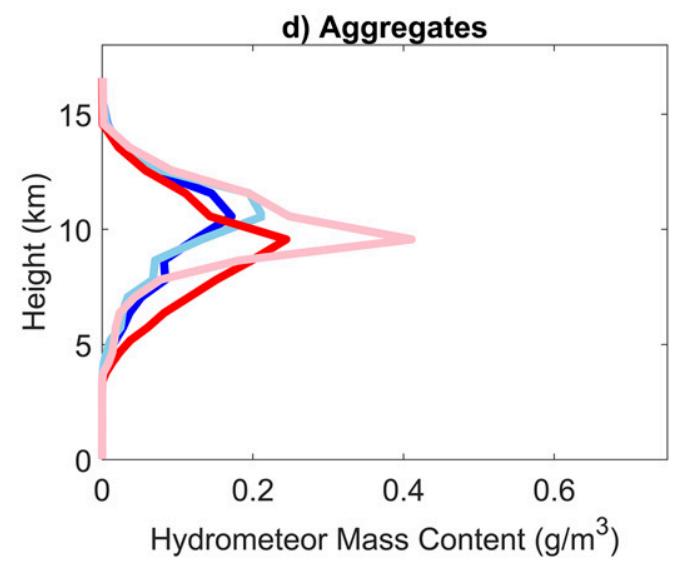

FIG. 3. Vertical profiles of average hydrometer content $\left(\mathrm{g} \mathrm{m}^{-3}\right)$ at $60 \mathrm{~min}$, for (a) rain, (b) hail, (c) graupel, and (d) aggregates.

high fall speed simulations (i.e., " $\mathrm{H}$ " simulations) split with distinct right and left movers, while neither of the low fall speed simulations (i.e., "L") exhibit a classic split. BULK-L remains a single cell storm and BIN-L develops some secondary convection that remains near to the main storm. At $60 \mathrm{~min}$, splitting in both BULK-H and BIN-H is apparent (Figs. 2a,c) and after $100 \mathrm{~min}$, BIN-H's left mover intensifies (Fig. 2c). Despite these differences, Fig. 2 also indicates that the right-mover updrafts are all quite similar. BULK-H and BIN-H have more total precipitation than BULK-L and BIN-L, respectively, but both bulk simulations have more precipitation than either bin simulation. Because the storms split, the precipitation fields of the high fall speed simulations cover much more area than their low fall speed counterparts. BULK-H and BIN-H have precipitation fields of approximately the same area; and despite the disorganized secondary convection that forms in BIN-L, BULK-L's precipitation field is roughly the same area (Fig. 2). Nearly all precipitation reaches the surface as rain except for a negligible amount of hail early in the bulk simulations. The conclusion we draw from Fig. 2 is that the behavior of simulated supercells depends more strongly on fall speed parameterization than on microphysics scheme type in our simulations. This conclusion is significant as it indicates how critical the fall speeds are to the evolution of supercell thunderstorms.

Most of the differences between our simulations can be attributed to splitting. Thus, in the remainder of this work, we further investigate the differences among the simulations and discuss why $\mathrm{H}$ simulations split and $\mathrm{L}$ simulations do not. To suggest why the left mover does or does not form, we will first investigate the microphysical behavior of our storms and then link the microphysics back to storm dynamics.

\section{b. Microphysics}

The direct result of differing fall speeds should be on the vertical structure of hydrometeors in the storms. Higher fall speeds will logically allow big ice to precipitate faster out of the anvil and core where it can begin to melt and contribute to increased rain near the surface. This effect is observed in the storms beginning at about $30 \mathrm{~min}$ (not shown). At $60 \mathrm{~min}$, we see increased 

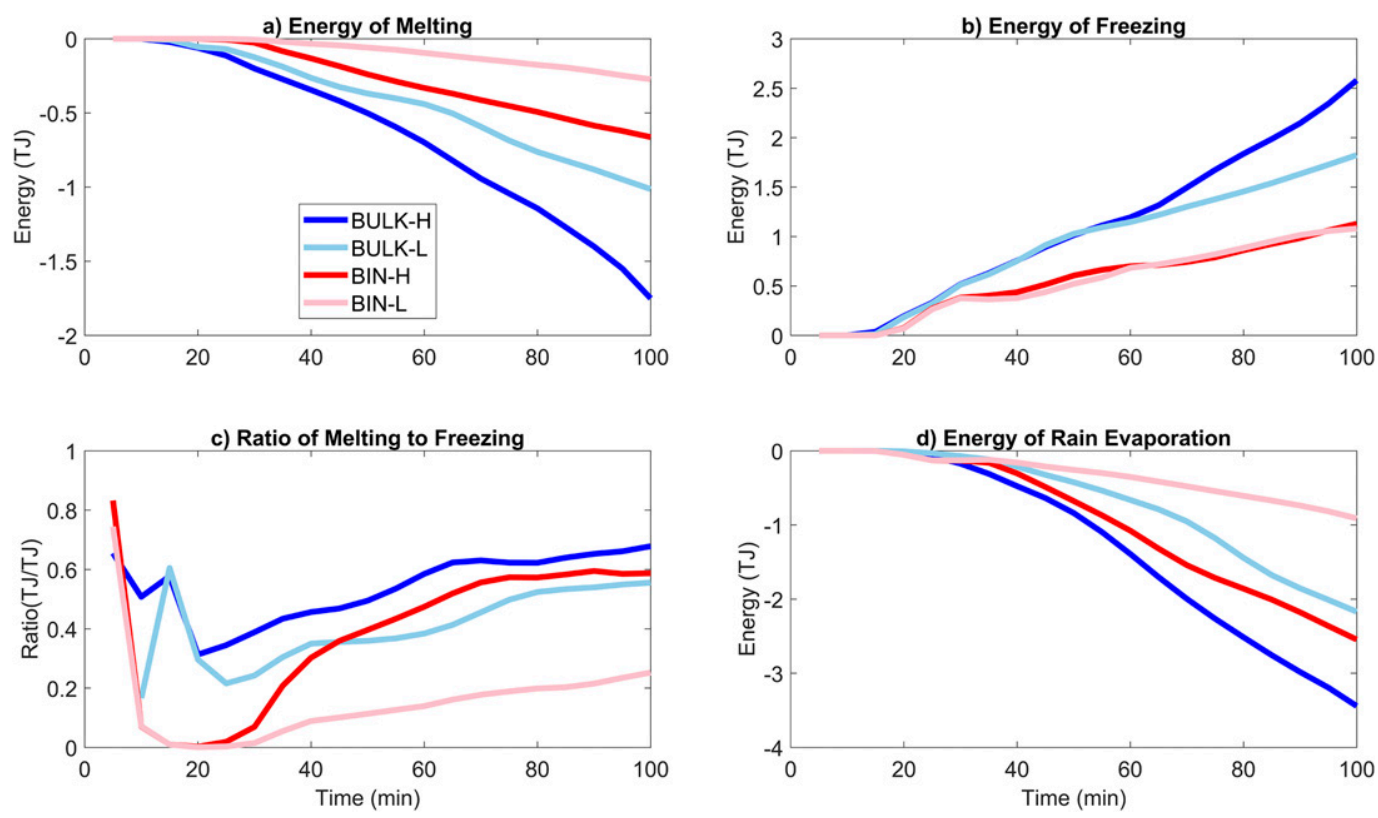

FIG. 4. The latent heating (TJ) associated with (a) melting, (b) freezing, and (d) evaporation. (c) The ratio of melting to freezing.

rainwater content in both $\mathrm{H}$ simulations compared to the L simulations (Fig. 3a). At this same time, we see higher ice water contents in $\mathrm{H}$ compared to $\mathrm{L}$ at lower elevations for all three species: hail, graupel, and aggregated snow (Figs. 3b-d). There are some clear shifts between the BULK and BIN simulations. BULK has more hail and less graupel than BIN, but the summation of the two species is about the same. Additionally, the BIN simulations have a more prominent downward shift of the ice mass, particularly for hail and aggregates. This may be because for small hydrometeor sizes the difference in fall speeds is greater between $\mathrm{H}$ and $\mathrm{L}$ for the BIN simulations (Figs. 1a,c,e). Finally, the simulations could develop different mean hydrometeor size that would also affect the fall speeds, but this seems to be a secondary effect on the profiles shown in Fig. 3. BIN-H has smaller big ice at low levels than BIN-L that partly offsets the higher fall speeds in BIN-H; however, BULK-H and BULK-L have more similar sizes (not shown).

One immediate impact of these differences in hydrometeor mass content is the rate of melting. Figure $4 \mathrm{a}$ indicates that melting is sensitive to the fall speed relationship from the start with BULK-H having the most melting, followed by BULK-L, BIN-H, and BIN-L. An increase in evaporation of rain follows from the greater melting of precipitating ice (Fig. 4d). BULK-L has more melting than BIN-H, but BIN-H has more evaporation than BULK-L. Due to the differing ice nucleation schemes and riming and aggregation schemes, BIN-H has smaller mean raindrop diameters (not shown). Thus, evaporation occurs more rapidly in BIN-H despite less melting. The high fall speed storms consistently evaporate more rain than their low fall speed counterparts.

The additional melting in $\mathrm{H}$ simulations compared to their L counterparts is not driven by additional freezing. Freezing primarily occurs in the updrafts, and total freezing is closely linked to updraft mass flux. As previously shown, the updrafts in the right movers are all quite similar (Fig. 2). Furthermore, since we did not alter any of the properties of the warm phase hydrometeors, we expect the total freezing in the initial development of the storms to be similar. As expected, Fig. $4 \mathrm{~b}$ shows the freezing in the storms depends more on the microphysics scheme than the fall speed relationship until splitting occurs. For BULK-H, its freezing is nearly identical to BULK-L until $60 \mathrm{~min}$, when its left mover begins to intensify. For BIN-H, its freezing is very similar to BIN-L, at some points even less, until after $100 \mathrm{~min}$ when its left mover intensifies.

Figure $4 \mathrm{c}$ also shows the ratio of melting to freezing. This metric is introduced as a simple way of examining the upward convective flux of liquid to the downward settling of ice. In all cases, this ratio indicates that the storms freeze more water than they melt. The high fall speed simulations melt a much higher fraction of the mass frozen than do the low fall speed simulations, which is logically consistent with our previous findings. After $40 \mathrm{~min}$, BIN-H surpasses BULK-L so the ratio of 

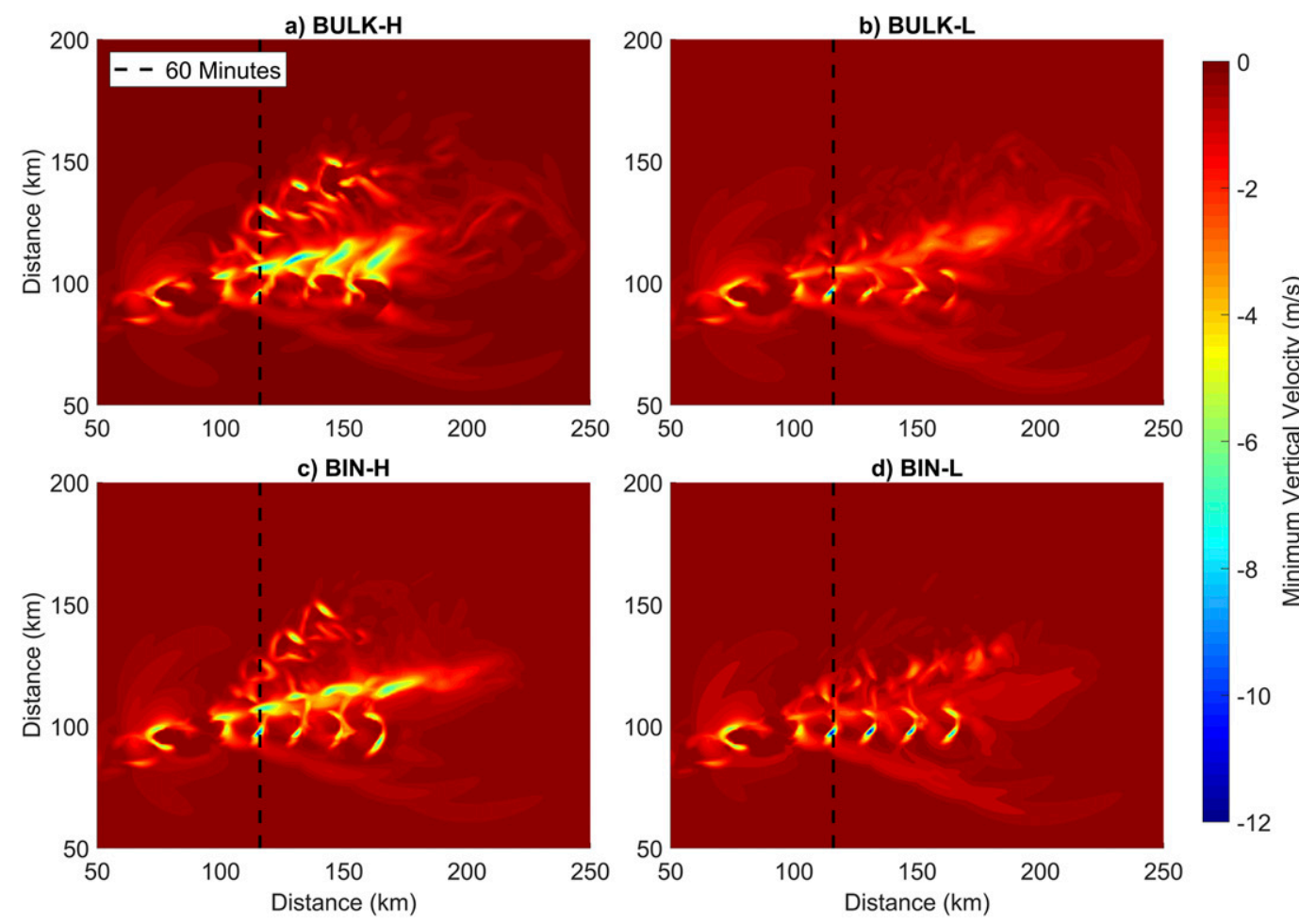

FIG. 5. As in Fig. 2, but for the strongest downdraft below $5 \mathrm{~km}$. The vertical velocity data are taken every $15 \mathrm{~min}$ and cut off at $100 \mathrm{~min}$.

melting to freezing is determined by the fall speed relationships first and the parameterization scheme second (i.e., BULK-H, BIN-H, BULK-L, BIN-L).

\section{c. Downdrafts and cold pools}

The consequence of the increase in melting and evaporation in the high fall speed simulations is an increase in latent cooling (Fig. 4). The increase in latent cooling coupled with an increase in condensate loading (implied in Fig. 3) leads to the formation of stronger downdrafts at low levels (Fig. 5). For the first $30 \mathrm{~min}$ of the simulation, all simulations have almost identical downdrafts below $5 \mathrm{~km}$. From $30 \mathrm{~min}$ to the split becoming apparent at $60 \mathrm{~min}, \mathrm{BULK}-\mathrm{H}$ and BIN-H have discernably stronger and more widespread downdrafts (Figs. 5a,c) than BULK-L and BIN-L (Figs. 5b,d) in the lowest $5 \mathrm{~km}$. Additionally, the structure of the downdrafts is markedly different. The $\mathrm{H}$ simulations have much larger and more intense downdrafts on the northern (forward) flank of their right movers than the $\mathrm{L}$ simulations in the lowest $5 \mathrm{~km}$.

The next connection is from increased downdrafts and melting to stronger cold pools; more melting cools the air and stronger downdrafts force it to the surface where it spreads into the cold pool and can excite new convection. Figure 6 shows these effects occur in our simulations. At $100 \mathrm{~min}, \mathrm{BULK}-\mathrm{H}$ has a cold pool with an area of $4639 \mathrm{~km}^{2}$ (cold pool area defined as grid boxes at the surface with a temperature deviation of more than $-0.5 \mathrm{~K}$ ) and a maximum temperature deviation of $-8 \mathrm{~K}$ from the background (Fig. 6a). BIN-H and BULK-L both have smaller cold pools, 3046 and $3521 \mathrm{~km}^{2}$, respectively, with maximum deviations of $-4 \mathrm{~K}$ (Figs. 6b,c, respectively). BIN-L has the smallest cold pool, $1639 \mathrm{~km}^{2}$, and a maximum deviation of only $-2 \mathrm{~K}$ (Fig. 6d). The dynamic effect of these cold pools is also clear. In the $\mathrm{H}$ simulations, and to a lesser extent in BULK-L, the cold pools are pushing air outward, and then upward (as implied by convergence) at their edge. This is consistent with past research (Rotunno et al. 1988; Weisman and Rotunno 2004). In the H simulations, leftmover updrafts are situated on the edge of their respective cold pools (Fig. 6).

As discussed in the introduction, there have been conflicting conclusions drawn on the impact of hydrometeor size and fall speed on cold pool intensity in the past. Our results are in better agreement with those studies that associate higher fall speeds with colder cold pools (Bryan and Morrison 2012; Van Weverberg et al. 2012; Adams-Selin et al. 2013). However, we note that in our simulations, there is nearly complete melting of hail 

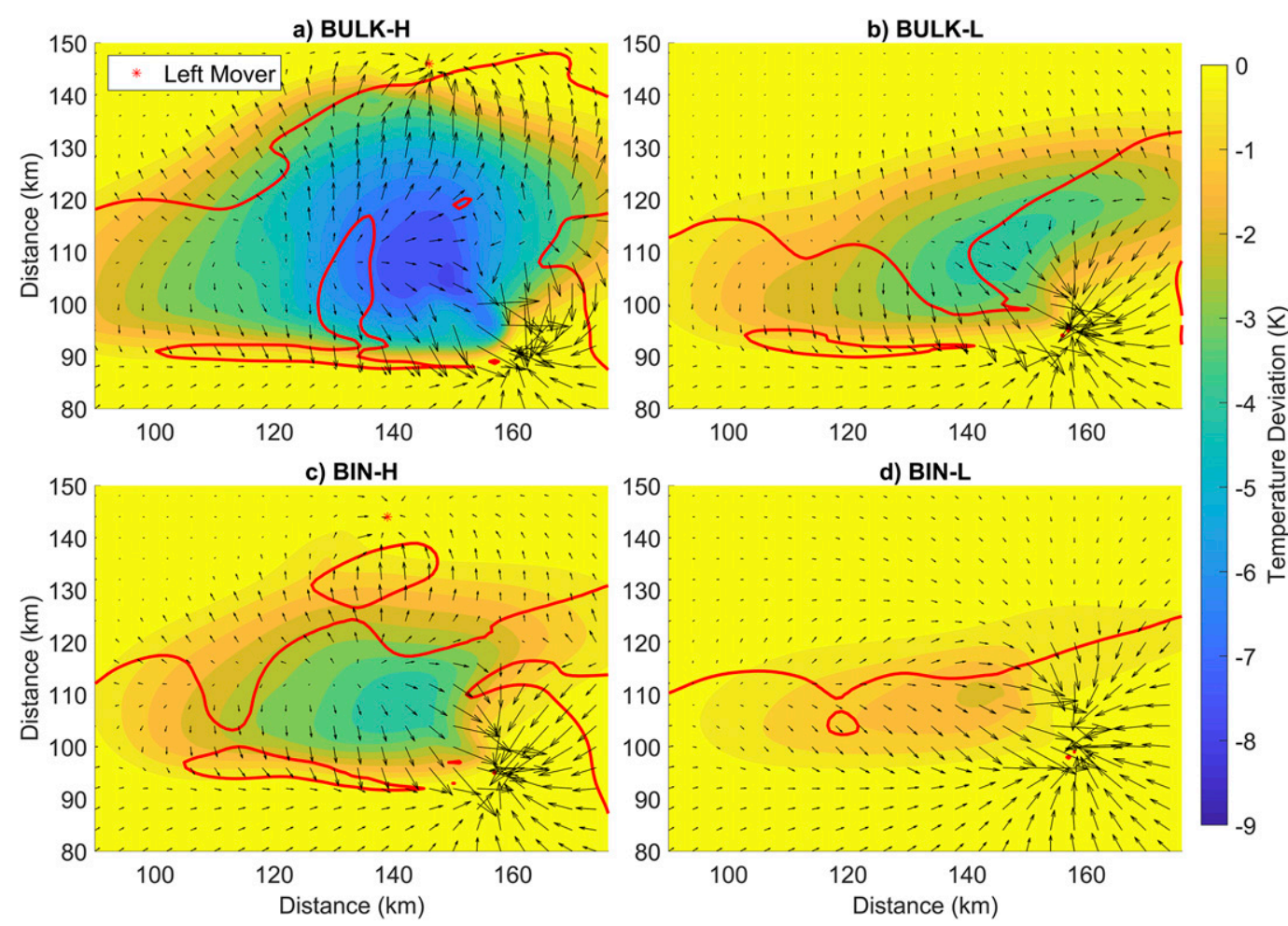

FIG. 6. Surface air temperature deviation at $100 \mathrm{~min}$ with surface winds, left movers in the high fall speed runs are marked. Red lines show regions where the magnitude of the horizontal vorticity matches or exceeds the low-level vertical wind shear.

and graupel in all simulations. This was not the case in van den Heever and Cotton (2004), Cohen and McCaul (2006), or Xue et al. (2017). If a significant fraction of our hail and graupel had remained frozen, then we may have expected results that were more in line with these studies.

\section{d. "Splitting"}

As we have shown, the $\mathrm{H}$ simulations have stronger cold pools due indirectly to higher fall speeds of big ice. These stronger cold pools lead to the formation of additional convective cells in the $\mathrm{H}$ simulations. In many respects, these new convective cells resemble left movers that have split from their parent supercell. They have anticyclonic updraft vorticity, they move at an acute angle to their parent cell, and they are generally weaker than their parent supercell. However, the formation and maintenance of these cells appears to be largely driven by cold pool dynamics (see next). So, by "split" we simply mean the generation of a leftward moving secondary storm or storms by any mechanism.

Figure 7 shows the evolution of updrafts at $1.4 \mathrm{~km}$ for BULK-H and BULK-L. BIN-H and BIN-L behave similarly to BULK-H and BULK-L, respectively, and are not shown. Both BULK-H and BULK-L have a main updraft and a smaller, distinct updraft developing on the north side of the main updraft at $50 \mathrm{~min}$ (Figs. 7a,d). This smaller updraft would seem to be the beginning of the left mover. However, $10 \mathrm{~min}$ later (Figs. 7b,e) these traditional left movers have dissipated while a third updraft is forming farther to the north along the edge of the cold pool in BULK-H. By 75 min (Figs. 7c,f), the traditional left mover has all but dissipated while the "true" left mover in BULK-H is still on the cold pool edge and intensifying. Bulk-H's left mover is even beginning to contribute to the cold pool.

Traditional supercell splitting in high shear environments is driven by a top-down process where heavy precipitation and downdrafts act to separate regions of oppositely signed updraft vorticity. It is certainly reasonable to imagine that the changes to the precipitation properties we have shown above could result in favorable conditions for such processes. Figures 8 and 9 show height versus meridional distance from both BULK and BIN simulations of zonal maximum updraft speed at several times before and during the initial generation of new convection in the $\mathrm{H}$ simulations. In all simulations, the main updraft is adjacent to an area of enhanced vertical velocity just to its 


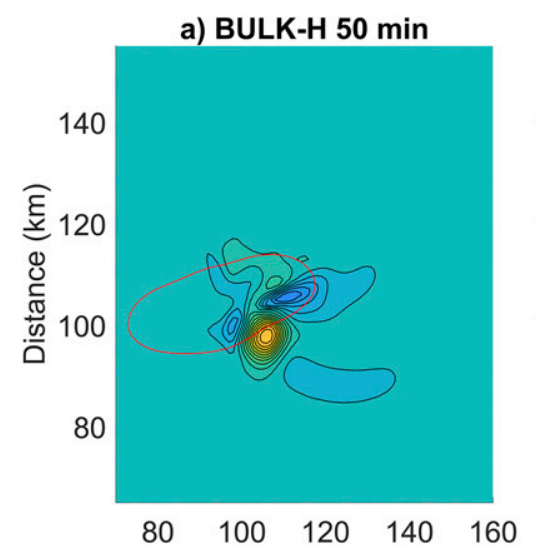

d) BULK-L $50 \mathrm{~min}$

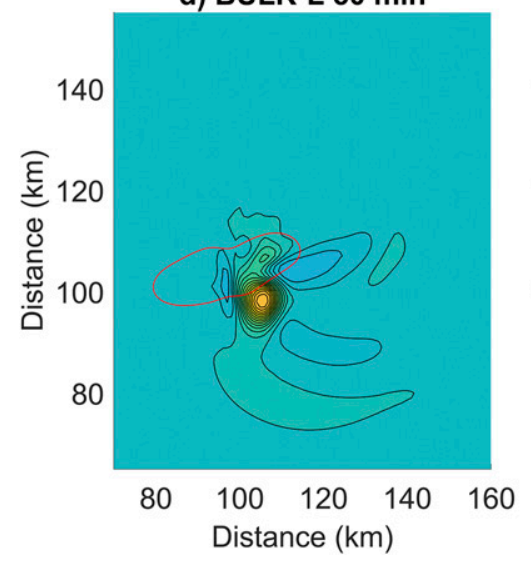

b) BULK-H $60 \mathrm{~min}$
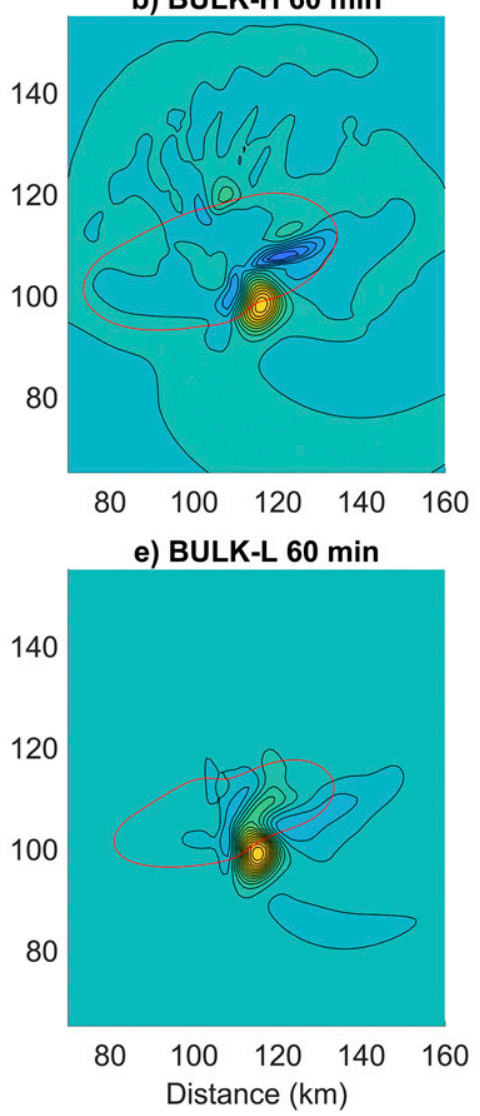

c) BULK-H $75 \mathrm{~min}$

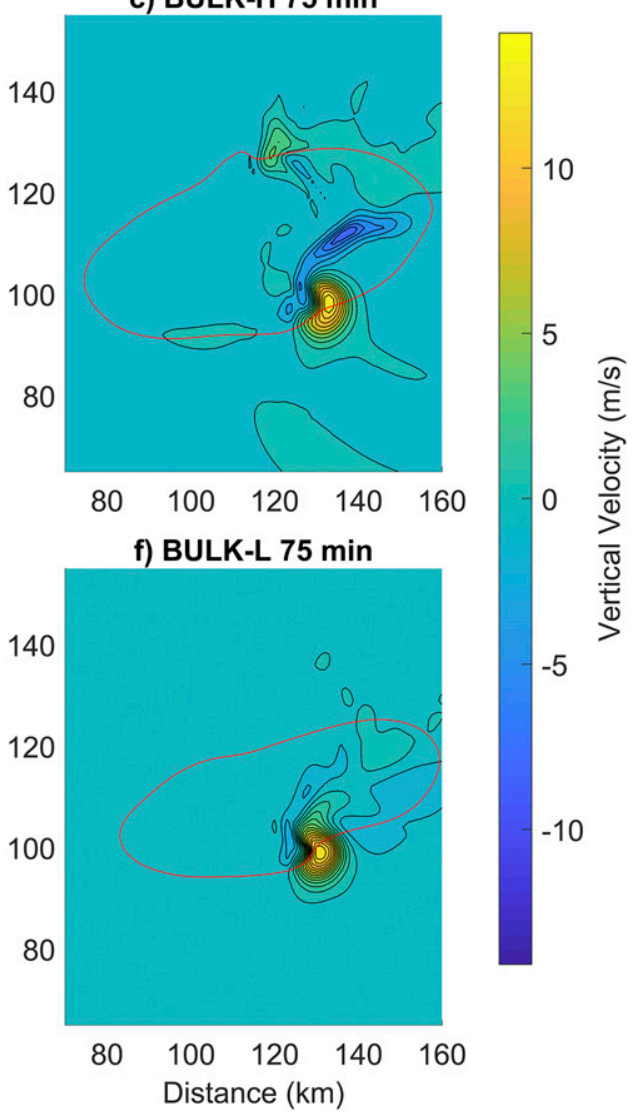

FIG. 7. Vertical velocity at $1.4 \mathrm{~km}$ and cold pool contour at a deviation of $-0.5 \mathrm{~K}$.

north (seen as a spreading of contours to the right of in the figure; the "traditional" left mover). With time, this adjacent velocity region descends slightly. In the $\mathrm{H}$ simulations, this adjacent velocity max appears to excite new surface-based convection at the leading edge of the cold pool (the "true" left mover). This new convection grows as it moves north of the main updraft. Figure 6 includes an outline of the region whose surface-to- $500 \mathrm{~m}$ vorticity matches the magnitude of the environmental shear in that same layer. Canonically, RKW theory (Weisman and Klemp 1984, 1982) predicts that maintenance of new convection is favored in regions whose low-level vorticity balances the shear. These conditions only appear to be met at the northern flank of the cold pool by $\mathrm{H}$ simulation storms. So, Figs. 6, 8, and 9 suggest that splitting in the $\mathrm{H}$ simulations is due either to enhanced excitation of new surface-based convection by a subtly descending northern downdraft (Figs. 8 and 9) and/or due to better convective maintenance mechanisms provided by the stronger cold pools (Fig. 6). Either way, the splits appear to be similar to the mechanisms proposed to result in a supercell flanking a squall
(Klemp and Wilhelmson 1978; Wilhelmson and Klemp 1978). Although, we reiterate that it is not precisely our intention to prove why sustained split convection exists, but rather, it is to point out the more novel result that simulating splitting can depend on fall speed choices in at least some cases.

\section{Conclusions}

Model simulations of a supercell were conducted with the Regional Atmospheric Modeling System (RAMS), which has a double-moment bulk microphysics scheme as well as a bin microphysics scheme. Before alterations were made, the bulk scheme simulated a splitting supercell whereas the bin scheme did not. These schemes have differing built-in diameter-fall speed relationships for aggregated snow, graupel, and hail. Additional simulations were run in which the diameter-fall speed relationships in each scheme were modified to be more like the other. Both high fall speed simulations developed defined left movers while neither low fall speed simulation did. We conclude for this case that the cause of the starkly different bin and bulk simulations was a result 

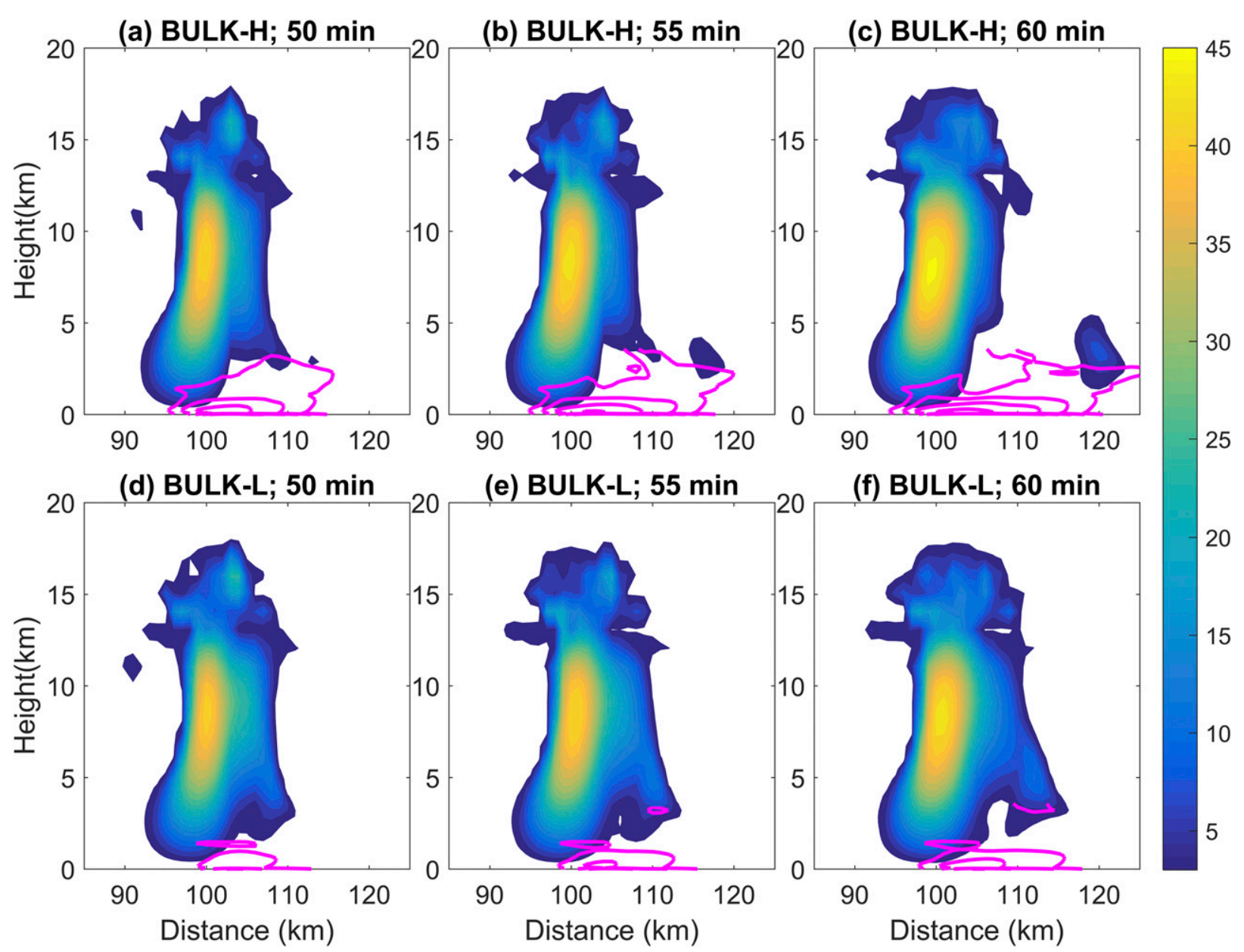

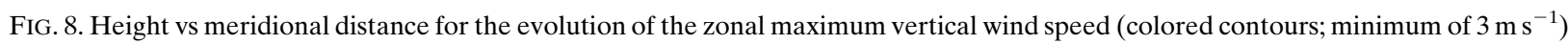
and maximum potential temperature depression every $1 \mathrm{~K}$ (magenta contours) in BULK-H and BULK-L.

of their choice of diameter-fall speed relationships for ice hydrometeors, and not the scheme design itself. Such a result suggests that the fundamentally different design of bulk and bin schemes may be less important than the assumptions about hydrometeor properties that they make.

We investigated why the diameter-fall speed relationships had such a large impact on the supercell development. We suggest that the following chain of events caused the high fall speed simulations to split. Higher fall speeds led to more hydrometeor mass at low levels, which led to greater melting and evaporation. Along with consequently larger condensate loading, this latent cooling led to stronger downdrafts, which led to larger and colder cold pools. These stronger cold pools intensified the left movers in simulations with high fall speeds. The splitting of these storms was described.

These results lead us to make several broad suggestions. First, in agreement with recommendations by Fan et al. (2016), more empirical data on ice diameter-fall speed relationships should be collected. Many efforts in this regard are currently under way (Cheng et al. 2015; Heymsfield et al. 2018; Westbrook and Sephton 2017). Second, while in our simulations the mass-diameter and velocity-diameter relationships were independent, we know that they should instead be linked and both depend on ice density. Ice density is usually prescribed, but more microphysics schemes may need to include ways to diagnose or predict ice density in order to have better relationships between hydrometeor size, mass, and velocity, such is currently done by the P3 bulk microphysics scheme (Morrison and Milbrandt 2015). Finally, care should be taken when comparing microphysics schemes, particularly bin and bulk schemes. Here we have shown that the primary differences in the storm evolution did not come from the large differences associated with the scheme type, but rather to one assumption that both schemes needed to make. 

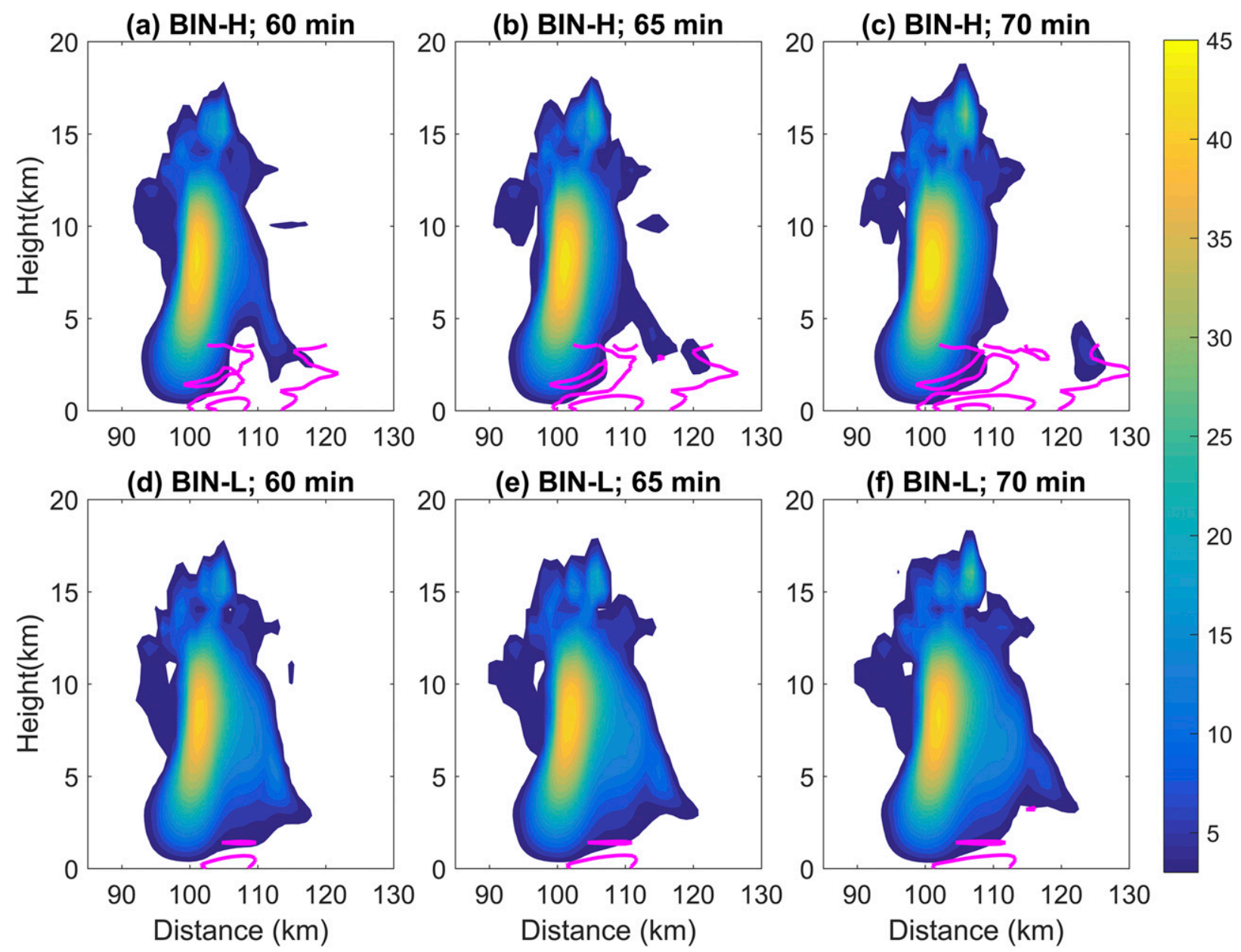

FIG. 9. As in Fig. 8, but for the BIN-H and BIN-L.

Acknowledgments. This work was supported by the University of California Davis. We also thank Susan van den Heever for helpful discussions at the onset of this work. The authors also thank three anonymous reviewers for their helpful comments. ALI designed and ran the model experiments, and performed the initial analysis. NMF performed the in-depth analysis with supervision from MRI. NMF wrote the original draft and ALI and MRI reviewed and edited the manuscript. The current version of RAMS is publicly available at vandenheever.atmos.colostate.edu/ vdhpage/ rams.php. Model simulations are available for download at adele.faculty.ucdavis.edu/data-access/. Plot data are available in the Dash FAIR-aligned data repository at dash.ucdavis.edu: https://doi.org/10.25338/ B8RC84.

\section{REFERENCES}

Adams-Selin, R. D., S. C. van den Heever, and R. H. Johnson, 2013: Sensitivity of bow-echo simulation to microphysical parameterizations. Wea. Forecasting, 28, 1188-1209. https:// doi.org/10.1175/WAF-D-12-00108.1.

Bennetts, D. A., and F. Rawlins, 1981: Paramaterization of the icephase in a model of mid-latitude cumulonimbus convection and its influence on the simulation of cloud development. Quart. J. Roy. Meteor. Soc., 107, 477-502, https://doi.org/ 10.1002/qj.49710745302.

Bryan, G. H., and H. Morrison, 2012: Sensitivity of a simulated squall line to horizontal resolution and parameterization of microphysics. Mon. Wea. Rev., 140, 202-225, https://doi.org/ 10.1175/MWR-D-11-00046.1.

Cheng, K.-Y., P. K. Wang, and T. Hashino, 2015: A numerical study on the attitudes and aerodynamics of freely falling hexagonal ice plates. J. Atmos. Sci., 72, 3685-3698, https:// doi.org/10.1175/JAS-D-15-0059.1.

Cohen, C., and E. W. McCaul, 2006: The sensitivity of simulated convective storms to variations in prescribed single-moment microphysics parameters that describe particle distributions, sizes, and numbers. Mon. Wea. Rev., 134, 2547-2565, https:// doi.org/10.1175/MWR3195.1.

Cotton, W. R., and Coauthors, 2003: RAMS 2001: Current status and future directions. Meteor. Atmos. Phys., 82, 5-29, https:// doi.org/10.1007/s00703-001-0584-9.

Fan, J., L. R. Leung, Z. Li, H. Morrison, H. Chen, Y. Zhou, Y. Qian, and Y. Wang, 2012: Aerosol impacts on clouds and 
precipitation in eastern China: Results from bin and bulk microphysics. J. Geophys. Res., 117, D00K36, https://doi.org/ 10.1029/2011JD016537.

— , and Coauthors, 2015: Improving representation of convective transport for scale-aware parameterization: 1 . Convection and cloud properties simulated with spectral bin and bulk microphysics. J. Geophys. Res. Atmos., 120, 3485-3509, https:// doi.org/10.1002/2014JD022142.

—_, Y. Wang, D. Rosenfeld, and X. Liu, 2016: Review of aerosolcloud interactions: Mechanisms, significance, and challenges. J. Atmos. Sci., 73, 4221-4252, https://doi.org/10.1175/JAS-D16-0037.1.

Gilmore, M. S., J. M. Straka, and E. N. Rasmussen, 2004: Precipitation uncertainty due to variations in precipitation particle parameters within a simple microphysics scheme. Mon. Wea. Rev., 132, 2610-2627, https://doi.org/10.1175/ MWR2810.1.

Grant, L. D., and S. C. van den Heever, 2014: Microphysical and dynamical characteristics of low-precipitation and classic supercells. J. Atmos. Sci., 71, 2604-2624, https://doi.org/10.1175/ JAS-D-13-0261.1.

Harrington, J. Y., 1997: The effects of radiative and microphysical processes on simulated warm and transition season artic stratus. Ph.D. thesis, Colorado State University, 289 pp.

Heymsfield, A., M. Szakáll, A. Jost, I. Giammanco, and R. Wright, 2018: A comprehensive observational study of graupel and hail terminal velocity, mass flux, and kinetic energy. J. Atmos. Sci., 75, 3861-3885, https://doi.org/10.1175/JAS-D-18-0035.1.

Hill, G. E., 1974: Factors controlling the size and spacing of cumulus clouds as revealed by numerical experiments. J. Atmos. Sci., 31, 646-673, https://doi.org/10.1175/15200469(1974)031<0646:FCTSAS > 2.0.CO;2.

Igel, A. L., and S. C. van den Heever, 2017: The importance of the shape of cloud droplet size distributions in shallow cumulus clouds. Part I: Bin microphysics simulations. J. Atmos. Sci., 74, 249-258, https://doi.org/10.1175/JAS-D-15-0382.1.

_ M. R. Igel, and S. C. van den Heever, 2015: Make it a double? Sobering results from simulations using single-moment microphysics schemes. J. Atmos. Sci., 72, 910-925, https://doi.org/ 10.1175/JAS-D-14-0107.1.

Iguchi, T., T. Nakajima, A. P. Khain, K. Saito, T. Takemura, H. Okamoto, T. Nishizawa, and W.-K. Tao, 2012: Evaluation of cloud microphysics in JMA-NHM simulations using bin or bulk microphysical schemes through comparison with cloud radar observations. J. Atmos. Sci., 69, 2566-2586, https:// doi.org/10.1175/JAS-D-11-0213.1.

Johnson, J. S., Z. Cui, L. A. Lee, J. P. Gosling, A. M. Blyth, and K. S. Carslaw, 2015: Evaluating uncertainty in convective cloud microphysics using statistical emulation. J. Adv. Model. Earth Syst., 7, 162-187, https://doi.org/10.1002/2014MS000383.

Khain, A., M. B. Pinsky, and M. Shapiro, 2001: Graupel-drop collision efficiencies. J. Atmos. Sci., 58, 2571-2595, https://doi.org/ 10.1175/1520-0469(2001)058<2571:CROSGA >2.0.CO;2.

— A. Pokrovsky, M. Pinsky, A. Seifert, and V. Phillips, 2004: Simulation of effects of atmospheric aerosols on deep turbulent convective clouds using a spectral microphysics mixedphase cumulus cloud model. Part I: Model description and possible applications. J. Atmos. Sci., 61, 2963-2982, https:// doi.org/10.1175/JAS-3350.1.

, L. R. Leung, B. Lynn, and S. Ghan, 2009: Effects of aerosols on the dynamics and microphysics of squall lines simulated by spectral bin and bulk parameterization schemes. J. Geophys. Res., 114, D22203, https://doi.org/10.1029/2009JD011902.
_ - and Coauthors, 2015: Representation of microphysical processes in cloud-resolving models: Spectral (bin) microphysics versus bulk parameterization. Rev. Geophys., 53, 247-322, https://doi.org/10.1002/2014RG000468.

Klemp, J. B., and R. B. Wilhelmson, 1978: Simulations of rightand left-moving storms produced through storm splitting. J. Atmos. Sci., 35, 1097-1110, https://doi.org/10.1175/15200469(1978)035<1097:SORALM > 2.0.CO;2.

Li, X., W.-K. Tao, A. P. Khain, J. Simpson, and D. E. Johnson, 2009: Sensitivity of a cloud-resolving model to bulk and explicit bin microphysical schemes. Part I: Comparisons. J. Atmos. Sci., 66, 3-21, https://doi.org/10.1175/2008JAS2646.1.

Lilly, D. K., 1962: On the numerical simulation of buoyant convection. Tellus, 14, 148-172, https://doi.org/10.3402/ tellusa.v14i2.9537.

Loftus, A. M., W. R. Cotton, and G. G. Carrió, 2014: A triplemoment hail bulk microphysics scheme. Part I: Description and initial evaluation. Atmos. Res., 149, 35-57, https://doi.org/ 10.1016/j.atmosres.2014.05.013.

McFarquhar, G. M., and R. A. Black, 2004: Observations of particle size and phase in tropical cyclones: Implications for mesoscale modeling of microphysical processes. J. Atmos. Sci., 61, 422-439, https://doi.org/10.1175/1520-0469(2004) $061<0422$ :OOPSAP $>2.0$.CO;2.

Milbrandt, J. A., and M. K. Yau, 2005: A multimoment bulk microphysics parameterization. Part II: A proposed threemoment closure and scheme description. J. Atmos. Sci., 62 , 3065-3081, https://doi.org/10.1175/JAS3535.1.

Mitchell, D. L., 1996: Use of mass- and area-dimensional power laws for determining precipitation particle terminal velocities. J. Atmos. Sci., 53, 1710-1723, https://doi.org/10.1175/15200469(1996)053<1710:UOMAAD>2.0.CO;2.

Morrison, H., and W. W. Grabowski, 2007: Comparison of bulk and bin warm-rain microphysics models using a kinematic framework. J. Atmos. Sci., 64, 2839-2861, https://doi.org/10.1175/ JAS3980.

— microphysics schemes in idealized supercell thunderstorm simulations. Mon. Wea. Rev., 139, 1103-1130, https://doi.org/ 10.1175/2010MWR3433.1.

— , and J. A. Milbrandt, 2015: Parameterization of cloud microphysics based on the prediction of bulk ice particle properties. Part I: Scheme description and idealized tests. J. Atmos. Sci., 72, 287-311, https://doi.org/10.1175/JAS-D-14-0065.1.

Posselt, D. J., 2016: A Bayesian examination of deep convective squall-line sensitivity to changes in cloud microphysical parameters. J. Atmos. Sci., 73, 637-665, https://doi.org/10.1175/ JAS-D-15-0159.1.

Pruppacher, H., and J. D. Klett, 1997: Microphysics of Clouds and Precipitation: With an Introduction to Cloud Chemistry and Cloud Electricity. Springer, 954 pp.

Rotunno, R., J. B. Klemp, and M. L. Weisman, 1988: A theory for strong, long-lived squall lines. J. Atmos. Sci., 45, 463-485, https://doi.org/10.1175/1520-0469(1988)045<0463:ATFSLL> 2.0.CO;2.

Saleeby, S. M., and W. R. Cotton, 2004: A large-droplet mode and prognostic number concentration of cloud droplets in the Colorado State University Regional Atmospheric Modeling System (RAMS). Part I: Module descriptions and supercell test simulations. J. Appl. Meteor., 43, 182-195, https://doi.org/ 10.1175/1520-0450(2004)043<0182:ALMAPN>2.0.CO;2.

_ , and S. C. van den Heever, 2013: Developments in the CSURAMS aerosol model: Emissions, nucleation, regeneration, 
deposition, and radiation. J. Appl. Meteor. Climatol., 52, 26012622, https://doi.org/10.1175/JAMC-D-12-0312.1.

Seifert, A., and K. D. Beheng, 2006: A two-moment cloud microphysics parameterization for mixed-phase clouds. Part 1: Model description. Meteor. Atmos. Phys., 92, 45-66, https:// doi.org/10.1007/s00703-005-0112-4.

Shipway, B. J., and A. A. Hill, 2012: Diagnosis of systematic differences between multiple parametrizations of warm rain microphysics using a kinematic framework. Quart. J. Roy. Meteor. Soc., 138, 2196-2211, https://doi.org/10.1002/ qj.1913.

Smagorinsky, J., 1963: General circulation experiments with the primitive equations: I. The basic experiment. Mon. Wea. Rev., 91, 99-164, https://doi.org/10.1175/1520-0493(1963)091<0099: GCEWTP $>2.3 . \mathrm{CO} ; 2$.

Szyrmer, W., S. Laroche, and I. Zawadzki, 2005: A microphysical bulk formulation based on scaling normalization of the particle size distribution. Part I: Description. J. Atmos. Sci., 62, 4206-4221, https://doi.org/10.1175/JAS3620.1.

van den Heever, S. C., and W. R. Cotton, 2004: The impact of hail size on simulated supercell storms. J. Atmos. Sci., 61, 15961609, https://doi.org/10.1175/1520-0469(2004)061<1596: TIOHSO $>2.0 . \mathrm{CO} ; 2$.

Van Weverberg, K., A. M. Vogelmann, H. Morrison, and J. A. Milbrandt, 2012: Sensitivity of idealized squall-line simulations to the level of complexity used in two-moment bulk microphysics schemes. Mon. Wea. Rev., 140, 1883-1907, https://doi.org/10.1175/MWR-D-11-00120.1.
Wang, Y., J. Fan, R. Zhang, L. R. Leung, and C. Franklin, 2013: Improving bulk microphysics parameterizations in simulations of aerosol effects. J. Geophys. Res. Atmos., 118, 53615379, https://doi.org/10.1002/jgrd.50432.

Weisman, M. L., and J. B. Klemp, 1982: The dependence of numerically simulated convective storms on vertical wind shear and buoyancy. Mon. Wea. Rev., 110, 504-520, https://doi.org/ 10.1175/1520-0493(1982)110<0504:TDONSC >2.0.CO;2.

$\longrightarrow$, and $—$ 1984: The structure and classification of numerically simulated convective storms in directionally varying wind shears. Mon. Wea. Rev., 112, 2479-2498, https://doi.org/ 10.1175/1520-0493(1984)112<2479:TSACON>2.0.CO;2.

— lines" Revisited. J. Atmos. Sci., 61, 361-382, https://doi.org/ 10.1175/1520-0469(2004)061<0361:ATFSLS > 2.0.CO;2.

Westbrook, C. D., and E. K. Sephton, 2017: Using 3-D-printed analogues to investigate the fall speeds and orientations of complex ice particles. Geophys. Res. Lett., 44, 7994-8001, https://doi.org/10.1002/2017GL074130.

Wilhelmson, R. B., and J. B. Klemp, 1978: A numerical study of storm splitting that leads to long-lived storms. J. Atmos. Sci., 35, 1974-1986, https://doi.org/10.1175/1520-0469(1978)035<1974: ANSOSS $>2.0$.CO;2.

Xue, L., and Coauthors, 2017: Idealized simulations of a squall line from the MC3E field campaign applying three bin microphysics schemes: Dynamic and thermodynamic structure. Mon. Wea. Rev., 145, 4789-4812, https://doi.org/10.1175/ MWR-D-16-0385.1. 